This is an electronic reprint of the original article. This reprint may differ from the original in pagination and typographic detail.

Author(s): Cortázar, O. D.; Megía-Macías, A.; Tarvainen, Olli; Kalvas, Taneli; Koivisto, Hannu

Title: $\quad$ Correlations between density distributions, optical spectra, and ion species in a hydrogen plasma (invited)

Year: $\quad 2016$

Version:

Please cite the original version:

Cortázar, O. D., Megía-Macías, A., Tarvainen, O., Kalvas, T., \& Koivisto, H. (2016). Correlations between density distributions, optical spectra, and ion species in a hydrogen plasma (invited). Review of Scientific Instruments, 87(2), Article 02A704. https://doi.org/10.1063/1.4931720

All material supplied via JYX is protected by copyright and other intellectual property rights, and duplication or sale of all or part of any of the repository collections is not permitted, except that material may be duplicated by you for your research use or educational purposes in electronic or print form. You must obtain permission for any other use. Electronic or print copies may not be offered, whether for sale or otherwise to anyone who is not an authorised user. 


\section{AIP $\mid \begin{aligned} & \text { Review of } \\ & \text { Scientific Instruments }\end{aligned}$}

Correlations between density distributions, optical spectra, and ion species in a hydrogen plasma (invited)

O. D. Cortázar, A. Megía-Macías, O. Tarvainen, T. Kalvas, and H. Koivisto

Citation: Review of Scientific Instruments 87, 02 A704 (2016); doi: 10.1063/1.4931720

View online: http://dx.doi.org/10.1063/1.4931720

View Table of Contents: http://scitation.aip.org/content/aip/journal/rsi/87/2?ver=pdfcov

Published by the AIP Publishing

\section{Articles you may be interested in}

Low energy ion distribution measurements in Madison Symmetric Torus plasmas

Phys. Plasmas 21, 062511 (2014); 10.1063/1.4883645

Ion distribution measurements to probe target and plasma processes in electronegative magnetron discharges. I. Negative ions

J. Appl. Phys. 109, 073302 (2011); 10.1063/1.3553846

A time-resolved laser induced fluorescence study on the ion velocity distribution function in a Hall thruster after a fast current disruption

Phys. Plasmas 16, 043504 (2009); 10.1063/1.3112704

The effects of plasma density and magnetic field on ion temperature and drift velocity in a LaB 6 direct current plasma

Phys. Plasmas 16, 023505 (2009); 10.1063/1.3076205

Investigation of the ion dynamics in a multispecies plasma under pulsed magnetic fields

Phys. Plasmas 11, 4515 (2004); 10.1063/1.1782193

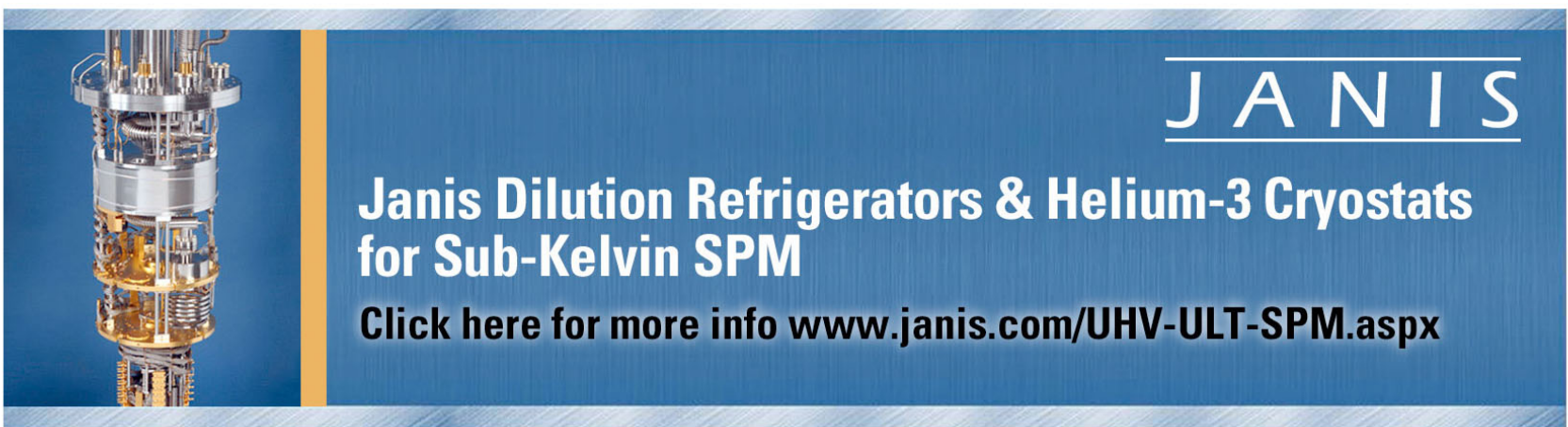




\title{
Correlations between density distributions, optical spectra, and ion species in a hydrogen plasma (invited)
}

\author{
O. D. Cortázar, ${ }^{1, a)}$ A. Megía-Macías, ${ }^{2, b)}$ O. Tarvainen, ${ }^{3}$ T. Kalvas, ${ }^{3}$ and H. Koivisto ${ }^{3}$ \\ ${ }^{1}$ INEI-Institute for Energy Research, University of Castilla-La Mancha, Camilo José Cela s/n, \\ 13170 Ciudad Real, Spain \\ ${ }^{2}$ ESS Bilbao Consortium, Polígono Ugaldeguren-III Pol. A 7B, 48170 Zamudio, Vizcaya, Spain \\ ${ }^{3}$ Department of Physics, University of Jyväskylä, PO Box 35 (YFL), 40500 Jyväskylä, Finland
}

(Presented 28 August 2015; received 18 August 2015; accepted 12 September 2015; published online 1 October 2015)

\begin{abstract}
An experimental study of plasma distributions in a $2.45 \mathrm{GHz}$ hydrogen discharge operated at $100 \mathrm{~Hz}$ repetition rate is presented. Ultrafast photography, time integrated visible light emission spectra, time resolved Balmer-alpha emission, time resolved Fulcher Band emission, ion species mass spectra, and time resolved ion species fraction measurements have been implemented as diagnostic tools in a broad range of plasma conditions. Results of plasma distributions and optical emissions correlated with $\mathrm{H}^{+}, \mathrm{H}_{2}^{+}$, and $\mathrm{H}_{3}^{+}$ion currents by using a Wien filter system with optical observation capability are reported. The magnetic field distribution and strength is found as the most critical factor for transitions between different plasma patterns and ion populations. () 2015 AIP Publishing LLC. [http://dx.doi.org/10.1063/1.4931720]
\end{abstract}

\section{INTRODUCTION}

Hydrogen discharges at $2.45 \mathrm{GHz}$ are one of the most popular plasmas for ion sources in a wide range of application fields from accelerators to industry. ${ }^{1-3}$ Recent results demonstrate the capabilities of $2.45 \mathrm{GHz}$ plasma sources for producing intense beams of molecular hydrogen ions $\mathrm{s}^{4,5}$ attracting the interest on these devices for manifold applications. ${ }^{6,7}$ Several plasma distributions where visible light emission suggests different dynamics of the $\mathrm{H}^{+}, \mathrm{H}_{2}^{+}$, and $\mathrm{H}_{3}^{+}$populations have been reported. ${ }^{8,9}$ Thus, visible light spectroscopy has been recently proposed as a non-invasive qualitative diagnostic for monitoring the plasma species fraction during ion source operation in a $2.45 \mathrm{GHz}$ hydrogen plasma discharge. ${ }^{10} \mathrm{We}$ report herein a study of the $\mathrm{H}^{+}, \mathrm{H}_{2}^{+}$, and $\mathrm{H}_{3}^{+}$current correlated with visible filtered, Balmer- $\alpha$ and Fulcher band emissions, and plasma distributions recently observed.

\section{EXPERIMENTAL SETUP}

The plasma source dimensions and characteristics have been presented in Ref. 11. An extraction electrode system and a Wien filter ion velocity analyzer with optical measurement capability have been used to perform the study. Figure 1 shows a half-section view of the experiment where the most important blocks can be seen: Plasma source + extraction, Wien filter, and Faraday's cup. Note the axial line of sight along the axis of the system. The characteristics and performance of the setup are described in detail in Ref. 10. The system can

Note: Invited paper, published as part of the Proceedings of the 16th International Conference on Ion Sources, New York, New York, USA, August 2015.

a)Author to whom correspondence should be addressed. Electronic mail: daniel.cortazar@uclm.es

b) Present address: CERN, BE-ABP-HSL Department, CH1211 Geneva, Switzerland. extract currents in the order of $1 \mathrm{~mA}$ analyzing the beam in two acquisition modes: spectrum or ion species evolution. In the spectrum mode, the Wien filter can obtain spectra of (singly charged) ion mass in a range between 1 and $20 \mathrm{amu}$. This operation mode is designed to be used by obtaining data from different consecutive pulses. The timing for the data acquisition must be specified. Once the spectrum is obtained and the ion species are identified, the voltages corresponding to each species can be used in the ion species evolution mode. In this mode, the system can acquire current vs. time signals for selected voltages allowing to obtain the temporal response of each ion species with $1 \mu \mathrm{s}$ resolution. The plasma electrode, extraction system, and Wien filter were designed using the IBSimu code. $^{12}$

\section{RESULTS}

A comprehensive study of the $\mathrm{H}^{+}, \mathrm{H}_{2}^{+}$, and $\mathrm{H}_{3}^{+}$spectra and currents correlated with visible (390-700 nm), Balmer- $\alpha$

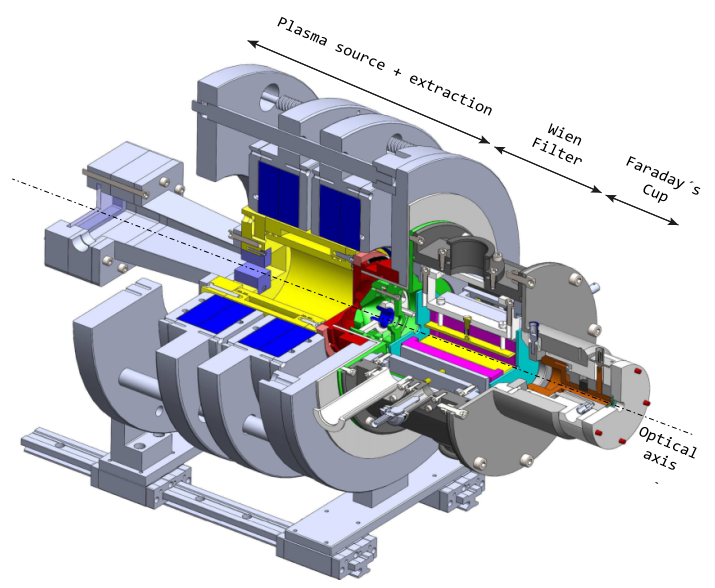

FIG. 1. Half-section of the experiment where the most important blocks can be seen: Plasma source + extraction, Wien filter, and Faraday's cup. 

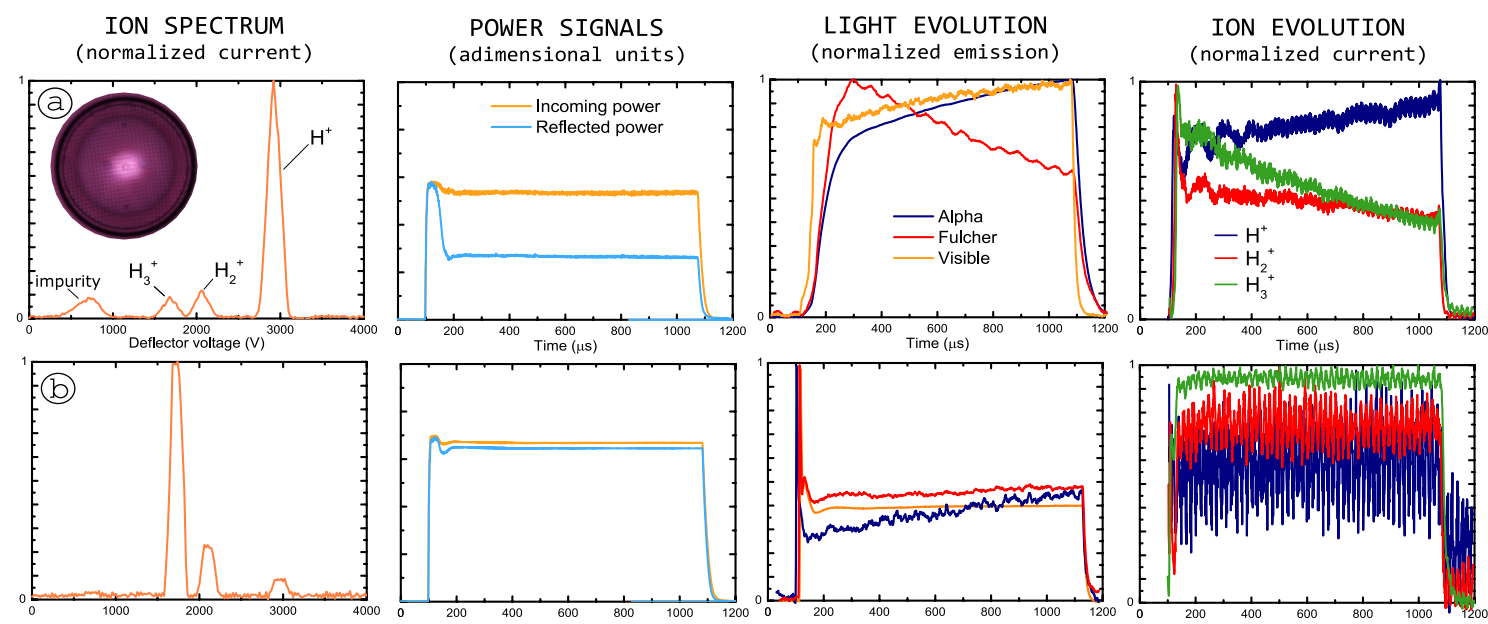

FIG. 2. Data arrangement for the two sets of plasma parameters where Column distribution is observed. Case (a): $3.8 \times 10^{-3}$ mbar of pressure and $1500 \mathrm{~W}$ of incoming power. Case (b): $8.5 \times 10^{-3}$ mbar of pressure and $2100 \mathrm{~W}$ of incoming power.

$(486.1 \mathrm{~nm})$, and Fulcher band emission (around $600 \mathrm{~nm}$ ) was conducted. The Balmer- $\alpha$ and Fulcher band signals were obtained using band pass filters (Thorlabs models FB488-10 with $488 \mathrm{~nm}$ central wavelength and $10 \mathrm{~nm}$ bandpass region and FB600-40 with $600 \mathrm{~nm}$ central wavelength and $40 \mathrm{~nm}$ bandpass region) and a photomultiplier tube. The study was carried out covering the full range of operation parameters where stable plasma distributions (Column, Hourglass, Slug, Fullchamber, Ring, Flower, YinYang, and Donut) are created and mainly determined by the magnetic field profile as previously reported. ${ }^{8,9}$ Pictures obtained with a regular camera are included in the following figures to facilitate the association with the corresponding plasma distributions. Incoming and reflected microwave powers were also measured to include the coupling characteristics.

Figure 2 shows a data arrangement for the two most significant parameter sets resulting to Column plasma distributions. Each row shows the ion spectrum obtained at the middle of the pulse (steady state stage), the coupling evolution by incoming and reflected power signals, the temporal evolution of light signals for visible, Balmer- $\alpha$, and Fulcher band, and the normalized temporal evolution of ion species currents for $\mathrm{H}^{+}, \mathrm{H}_{2}^{+}$, and $\mathrm{H}_{3}^{+}$. Case (a) corresponds to a high intensity light emission with a reasonable power coupling factor of $50 \%$ and (b) to a poor intensity case with a low coupling of $5 \%$. In case (a), the $\mathrm{H}^{+}$is predominant but $\mathrm{H}_{3}^{+}$ is the most intense ion current for the case (b). Moreover, the $\mathrm{H}^{+}$current and Balmer- $\alpha$ signals show both similar tempo- ral profiles and the molecular currents $\left(\mathrm{H}_{2}^{+}\right.$and $\left.\mathrm{H}_{3}^{+}\right)$follow the temporal behavior of Fulcher band emission even during the breakdown transient. For the case (a), Balmer- $\alpha$ shows a continuous increase while Fulcher band emission exhibits the inverse behavior with a fast increase during breakdown followed by a slow decay. For case (b), the Fulcher band signal follows the $\mathrm{H}_{3}^{+}$current evolution remaining constant during the entire pulse length while Balmer- $\alpha$ signal grows only slowly.

Figure 3 shows a similar data arrangement for the Hourglass plasma distribution. The predominance of $\mathrm{H}^{+}$production is shown with coupling factors of about $40 \%-45 \%$. The similarity of optical signals respect to ion currents is remarkable even during the transients.

Figure 4 shows data for the Slug plasma distribution. Although both cases present a $\mathrm{H}^{+}$predominance, (a) has a coupling factor of $70 \%$ while (b) barely reaches $10 \%$. The inversion of ratio between $\mathrm{H}_{2}^{+}$and $\mathrm{H}_{3}^{+}$and the considerable breakdown transient peak (in both light and current signals) for case (b) respect to (a) could be related to the coupling characteristics. The breakdown times and couplings suggest different ionization dynamics between for each case. However, the connection between ion currents and light signals is remarkable even during the breakdown transients.

Figure 5 shows data from the Fullchamber plasma distribution. It presents a $\mathrm{H}^{+}$predominance with coupling factor around $50 \%$. The follow-up between ion currents and light signals is again observable with exception of the fast pulse
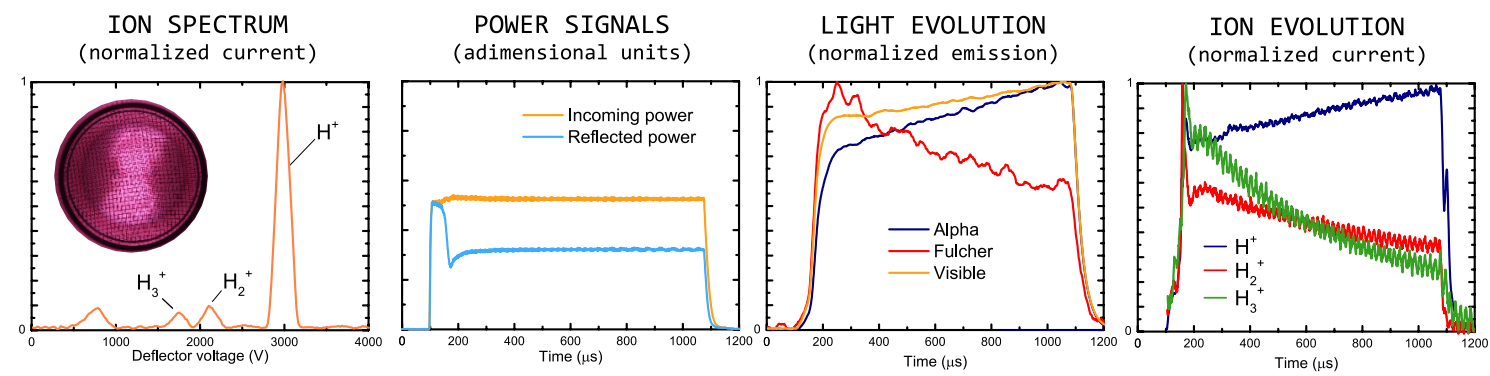

FIG. 3. Data arrangement for the set of plasma parameters where Hourglass distribution is observed: $3.8 \times 10^{-3} \mathrm{mbar}$ of pressure and $1500 \mathrm{~W}$ of incoming power. 

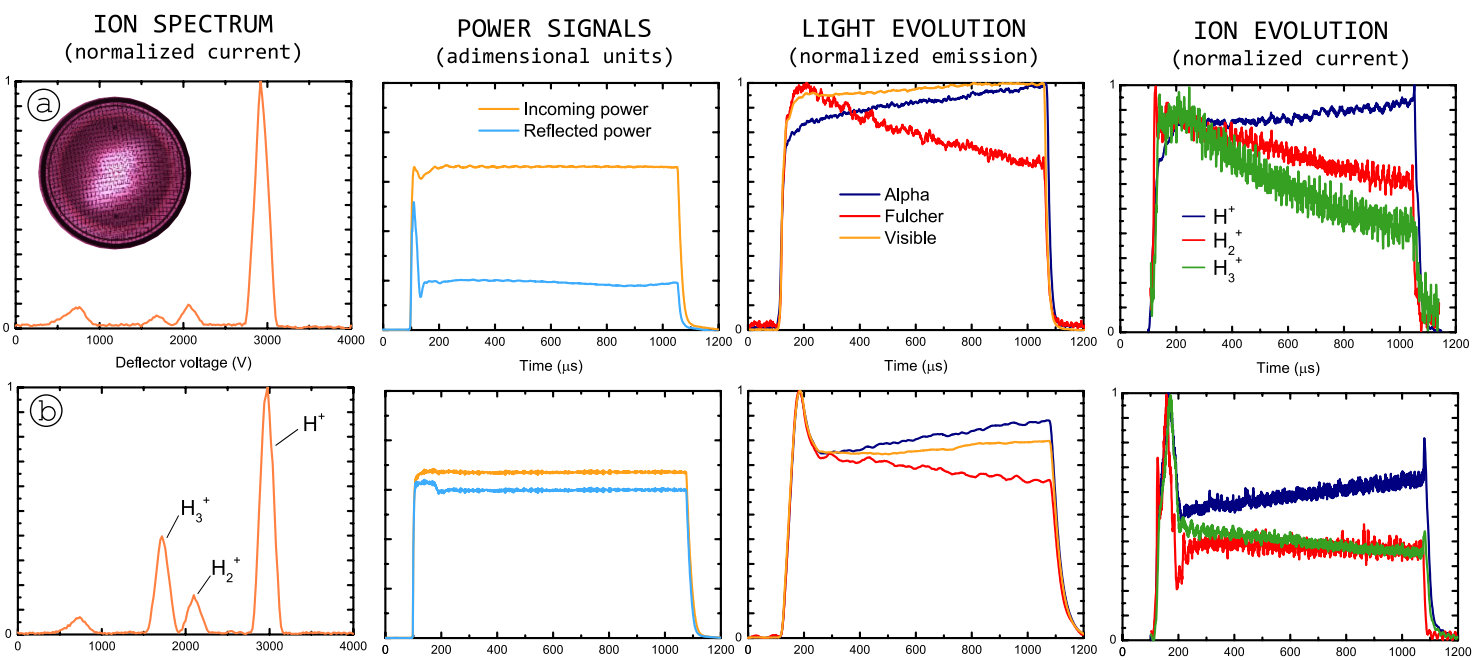

FIG. 4. Data arrangement for the two sets of plasma parameters where Slug distribution is observed. Case (a): $3.8 \times 10^{-3} \mathrm{mbar}$ of pressure and $600 \mathrm{~W}$ of incoming power. Case (b): $6.9 \times 10^{-3} \mathrm{mbar}$ of pressure and $1500 \mathrm{~W}$ of incoming power.
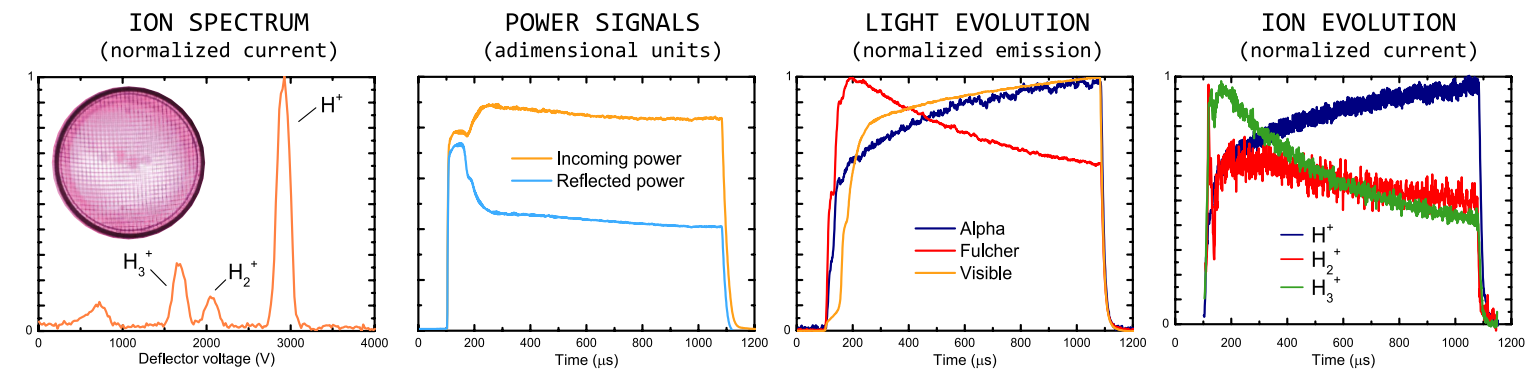

FIG. 5. Data arrangement for the set of plasma parameters where Fullchamber distribution is observed: $3.8 \times 10^{-3}$ mbar of pressure and $2550 \mathrm{~W}$ of incoming power.
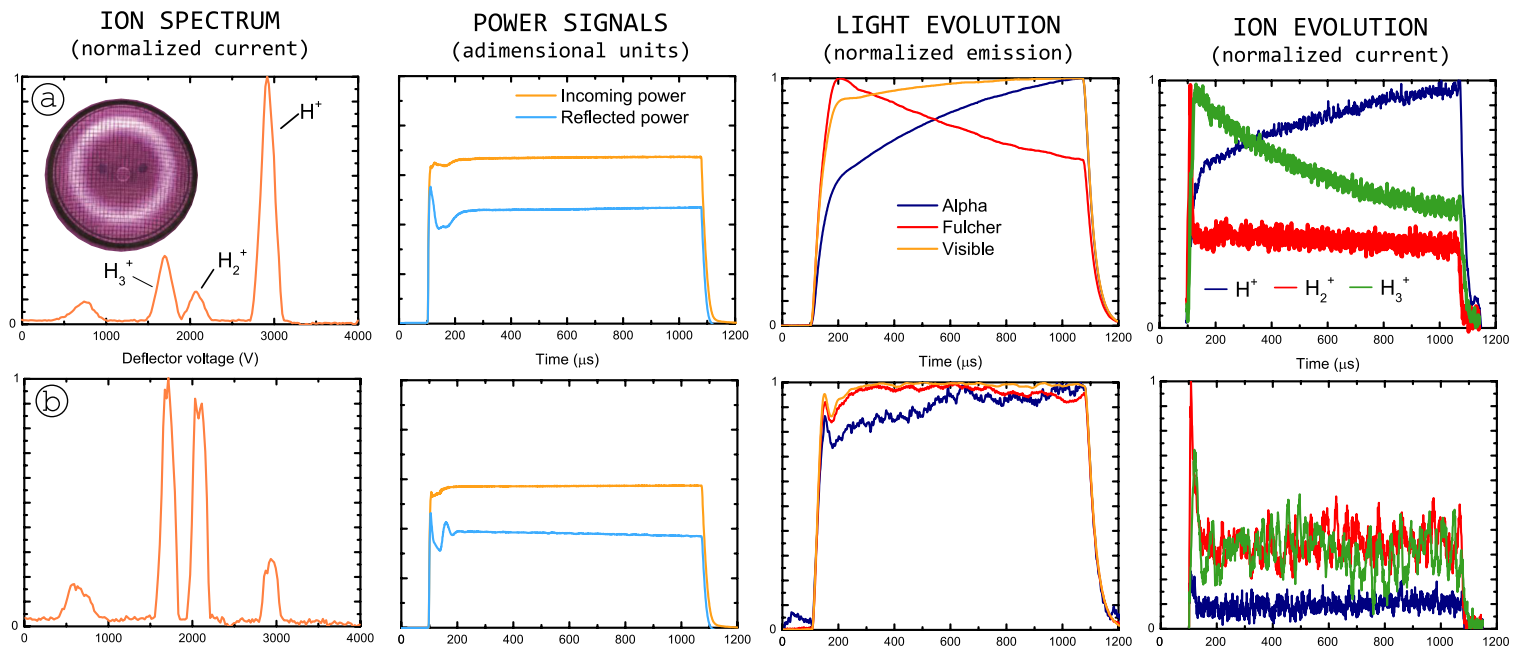

FIG. 6. Data arrangement for the two sets of plasma parameters where Ring distribution is observed. Case (a): $6.9 \times 10^{-3}$ mbar of pressure and $1500 \mathrm{~W}$ of incoming power. Case (b): $3.8 \times 10^{-3} \mathrm{mbar}$ of pressure and $1350 \mathrm{~W}$ of incoming power.

(less than $20 \mu \mathrm{s}$ ) during the breakdown for the $H_{2}^{+}$current that is not reflected in the Fulcher band signal.

Figure 6 shows data from the Ring plasma distribution. Although coupling factors of $40 \%$ are similar for both cases, the ratios of ion currents appear to be quite different. While the spectrum of case (a) presents a typical dominance of $\mathrm{H}^{+}$, the production of $\mathrm{H}_{2}^{+}$and $\mathrm{H}_{3}^{+}$is remarkably higher than $\mathrm{H}^{+}$ for the case (b). Other noticeable difference is the temporal behavior of ion currents, where a remarkable peak of $\mathrm{H}_{2}^{+}$ and $H_{3}^{+}$is produced during the first $20 \mu$ s of the breakdown process remaining practically constant after that. Otherwise, the tracing between optical signals and ion currents is good for the case (a) but the short pulse of $\mathrm{H}_{2}^{+}$during the breakdown is not reflected in the Fulcher band signal.

Figure 7 shows data for the Flower (a), YinYang (b), and Donut (c) plasma distributions. Coupling factors reaches 

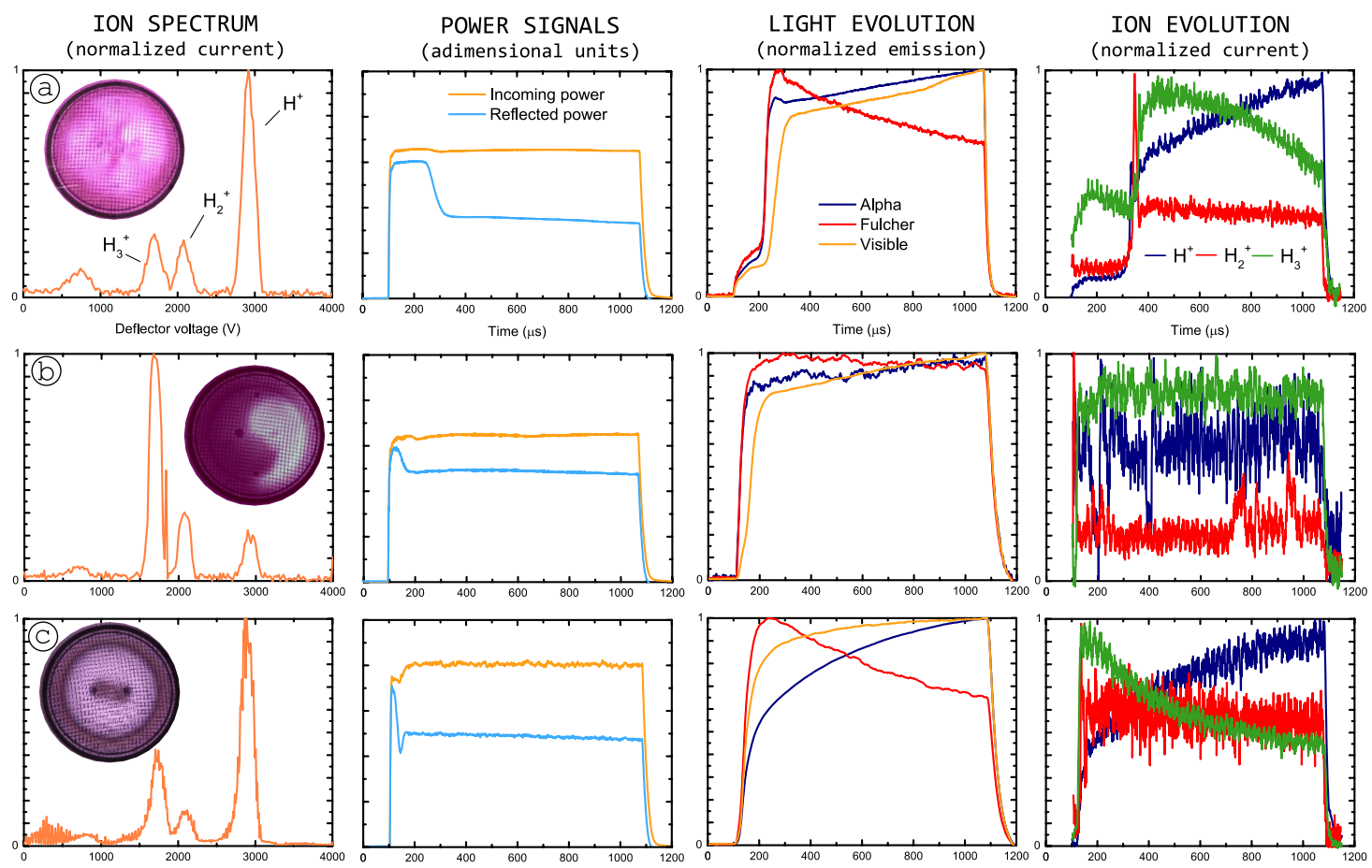

FIG. 7. Data arrangement for the Flower (a) $3.8 \times 10^{-3}$ mbar of pressure and $1500 \mathrm{~W}$ of incoming power, YinYang (b) $4.9 \times 10^{-3} \mathrm{mbar}$ of pressure and $1200 \mathrm{~W}$ of incoming power, and Donut (c) $9.6 \times 10^{-3}$ mbar of pressure and $2100 \mathrm{~W}$ of incoming power.

TABLE I. Maximum of species current values recorded for each plasma distribution during the steady state stage.

\begin{tabular}{lccc}
\hline \hline Distribution & $H^{+}(\mu \mathrm{A})$ & $H_{2}^{+}(\mu \mathrm{A})$ & $H_{3}^{+}(\mu \mathrm{A})$ \\
\hline Column $(a)$ & 140 & 15 & 12 \\
Column $(b)$ & 2 & 3 & 12 \\
Hourglass & 130 & 15 & 14 \\
Slug (a) & 180 & 18 & 10 \\
Slug (b) & 80 & 17 & 38 \\
Fullchamber & 80 & 10 & 20 \\
Ring (a) & 60 & 7 & 17 \\
Ring (b) & 2.5 & 6 & 7 \\
Flower & 50 & 12 & 13 \\
YinYang & 3 & 3.5 & 10 \\
Donut & 55 & 5.5 & 24 \\
\hline \hline
\end{tabular}

$45 \%, 25 \%$, and $50 \%$, respectively, where breakdown shows remarkable differences. Note the good correlation between optical signals and ion species currents and the spectacular predominance of $H_{3}^{+}$line for the YinYang (b) case. However, fast pulses of $H_{2}^{+}$at very beginning of breakdown are not resolved by optical signals as is clear for cases (a) and (b). It is also noticeable the long time required for breakdown in the case (a) where almost $400 \mu$ s are recorded in contrast with $50-80 \mu$ s for the other cases. Table I shows the peak values of the ion species currents obtained during the steady state stage corresponding to ion spectra of figures.

\section{DISCUSSION}

The experiments reveal a strong temporal correlation between ion species and optical emissions as has been pro- posed by the authors in previous works. ${ }^{9,10}$ The measurements clearly show that Balmer- $\alpha$ emission could be used as a representative signal of proton population in the plasma and the Fulcher band signal as a representative indication of molecular $H_{2}^{+}$and $H_{3}^{+}$ions' production. Moreover, the influence of the plasma distributions on the current species and its ratios is also demonstrated.

On the other hand, these results help to complete previous studies of Balmer- $\alpha$ and Fulcher band spatial distributions during plasma transients and steady-state stages ${ }^{8,9}$ that show how the molecular dissociation and atom excitation dynamics take place in time and space. An interesting example is the case of Column configuration shown in Fig. 2(b) where a low microwave coupling under a low gradient of magnetic field with a half-resonance $\left(B_{E C R} / 2\right)$ surface practically placed in the middle of the plasma chamber ${ }^{8}$ produces a remarkable ratio inversion with relative high $H_{3}^{+}$production. In addition, Ring and YingYang distributions show in Figs. 6(b) and 7(b) also inverted ratios where molecular ions dominate the spectra under a magnetic field topology completely out of resonance ${ }^{8}$ (with typical values around $60 \mathrm{mT}$ ) and low light intensity emission. Taking into account that the measurements were carried out on the axis and the plasma distributions for the late cases have pronounced radial profiles, the results suggest also unsuspected ion species radial distributions.

Moreover, are also noticeable the peaks of ion production during the breakdown process where $H_{2}^{+}$is remarkable for Column in Fig. 2(b), Hourglass in Fig. 3, Slug in Fig. 4(b), Fullchamber in Fig. 5, Ring in Figs. 6(a) and 6(b), Flower in Fig. 7(b), and YinYang in Fig. 7(c). These peaks are variable in duration between 20 and $100 \mu$ s and reach currents more than two times higher respect to values shown in Table I. 
However, for the range of experimental conditions under study, the data suggest that the inversion of fraction ratios between protons and molecular ions is associated to a drop in the proton production for determined plasma configurations.

Finally, the ion species ratio behaviors reported here open a lot of questions about the temporal and spatial dynamics of the Electron and Ion Energy Distribution Functions (EEDF and IEDFs) during transients and steady-state stages for this kind of plasma. The understanding of such dynamics may lead to some plasma tuning technical approaches for a wide range of applications.

${ }^{1}$ R. Gobin, N. Chauvin, O. Delferrière, T. O., and D. Uriot, in Proceedings of LINAC2012, Tel-Aviv, Israel, 2012.

${ }^{2}$ M. Cao, J. Cheng, C. Han, and L. Ji, Adv. Mater. Res. 1006, 193 (2014).

${ }^{3}$ J. Pelletier and A. Anders, IEEE Trans. Plasma Sci. 33, 1944 (2005).
${ }^{4}$ R. Xu, J. Zhao, S. Peng, Z. Yuan, Z. Song, J. Xu, and Z. Guo, Rev. Sci. Instrum. 79, 02B713 (2008).

${ }^{5}$ Y. Xu, S. Peng, H. Ren, J. Zhao, J. Chen, A. Zhang, T. Zhang, Z. Guo, and J. Chen, Rev. Sci. Instrum. 85, 02A943 (2014).

${ }^{6}$ R. Gobin, V. Blideanu, D. Bogard, G. Bourdelle, N. Chauvin, O. Delferrière, P. Girardot, J. Jannin, S. Langlois, D. Loiseau, B. Pottin, J.-Y. Rousse, and F. Senée, Rev. Sci. Instrum. 81, 02B301 (2010).

${ }^{7}$ J. Alonso, W. Barlleta, M. Toups, J. Conrad, Y. Liu, M. Bannister, C. Havener, and R. Vane, Rev. Sci. Instrum. 85, 02 A509 (2014).

${ }^{8}$ O. D. Cortázar, A. Megía-Macías, O. Tarvainen, A. Vizcaíno-de-Julián, and H. Koivisto, Plasma Sources Sci. Technol. 23, 065028 (2014).

${ }^{9}$ O. Cortázar, A. Megía-Macías, O. Tavainen, and H. Koivisto, Nucl. Instrum. Methods Phys. Res., Sect. A 781, 50 (2015).

${ }^{10}$ O. Cortázar, A. Megía-Macías, O. Tarvainen, T. Kalvas, and H. Koivisto, Rev. Sci. Instrum. 86, 083309 (2015).

${ }^{11}$ A. Megía-Macías, O. D. Cortázar, and A. Vizcaíno-de-Julián, Rev. Sci. Instrum. 85, 033310 (2014).

${ }^{12}$ T. Kalvas, O. Tarvainen, T. Ropponen, O. Steczkiewicz, J. Arje, and H. Clark, Rev. Sci. Instrum. 81, 02B703 (2010). 